\title{
COAXIAL-BASED ANTENNA PERFORMANCE IN MICROWAVE ABLATION
}

\author{
Olumide A. Towoju \\ Department of Mechanical Engineering \\ Adeleke University, Ede, Osun State, Nigeria
}

\begin{abstract}
The optimization of the performance of antenna utilized in microwave ablation therapy is a task which required continuous research, as the procedure is now being increasingly used in the treatment of tumours. The performance of the co-axial based antenna has been proven to be dependent on not just on properties of the dielectric and catheter materials, but also on the slot size, positioning, and geometry. The efficacy of the microwave ablation therapy is based on the developed temperature at the tumour site such as to cause necrosis. This is a direct function of the fraction of the input power which is converted into heat in the tissue.

The study is centered on the effect of using a number of slots with a constant cumulative size positioned at a constant relative position of $6 \mathrm{~mm}$ from the tip of the antenna. The slots were increased from one to six, and the effect on performance in microwave ablation was determined using COMSOL Multiphysics as the modelling tool.

The total power dissipation density was observed to increase with an increasing number of slots for a constant slot separation distance, however, an irregular pattern was observed for the case of uniform slot length of $1.05 \mathrm{~mm}$ along the coaxial antenna vertical axis.

The total power dissipation density during microwave ablation is a function of the number of slots if the separation gap between it is maintained at a constant value. Increased number of slots enhances the performance of the coaxial antenna.
\end{abstract}

Keywords-Antenna, Necrosis, Tumour

\section{INTRODUCTION}

Research has shown that ablation procedures are now being increasingly used for the treatment of tumour whose sizes are lesser than $7 \mathrm{~cm}$ "Campbell, et al, (2009)". it is increasingly being used in the treatment of tumours in organs in humans like the liver "Li, et al, (2017)" pancreas, kidney, and the heart. The human cells are temperature sensitive, and it is based on this concept that ablation is used in the treatment of tumours. The normal human body temperature is expected to be in the range of $(36.5-37.5){ }^{0} \mathrm{C}$ and the upset of this could be lethal.
One of the several ablation procedure techniques is microwave ablation therapy (MWA). It entails the use of electromagnetic radiations delivered through specially built antennas for the achievement of rapid temperature increment which is lethal to the concerned tissues (tumour) "Cornelis, et al; Gao, et al; Ibitoye, et al, $(2017,2017,2018)$ ". Temperature above $42{ }^{\circ} \mathrm{C}$ is said to be lethal to the human cells "Bettaeib and AverillBates; Cornelis, et al. (2015, 2017)", and the microwave ablation therapy seeks to offset this temperature at the tumour site(s) to achieve thermal lesion of such tumours.

Microwave ablation therapy uses either $915 \mathrm{MHz}$ and 2.45 $\mathrm{GHz}$ frequencies for its transmission as adopted by the statutory regulating body "Prakash; Baere and Deschamps; Deshazer, et al.; (2010, 2014, 2017)". The generated electromagnetic waves are independent of the tissue electrical conductivity "Higgins and Hong; Seror, (2015, 2015)", a boost for high reliability at higher intra-tumour temperatures, and an offering of a faster ablation time "Castle, et al, (2011)".

Different antenna geometry has been worked upon by several scholars who came up with two basic classes; the sleeve and the co-axial based antenna "Brace; Brace; Ibitoye, et al., (2010a, 2010b, 2018)". The antenna design among other parameters like the intensity of propagation of the electromagnetic radiation, the time duration of application, the relative permittivity and the catheter material are the determining factors of the thermal lesion extent that can be accomplished "Lerardi, et al.; Cornelis, et al.; Towoju and Petinrin, (2015, 2017, 2018)". The slot size, positioning, and geometry effect on the antenna have also been studied and shown to be one of the determining factors on the degree of thermal lesion that can be achieved during the microwave ablation therapy procedure "Towoju, et al., (2019)". The efficacy of the antenna is measured based on the electromagnetic power deposition per unit mass of the tissue "Bertram, et al., (2006)".

The ablation procedure is meant to be minimally invasive, and this is always a point of consideration in the design of the microwave ablation therapy antenna "Brace; Floridi, et al., (2010a, 2014)". And with the advancement in technology particularly in the field of image guidance, microwave ablation therapy is not just a viable alternative to the treatment of cancer tumours, it is more effective and safer "Higgins and Hong, (2015)". 


\section{International Journal of Engineering Applied Sciences and Technology, 2019 \\ Vol. 4, Issue 4, ISSN No. 2455-2143, Pages 6-11 \\ Published Online August 2019 in IJEAST (http://www.ijeast.com)}

The many advantages of the microwave ablation therapy like being less procedurally painful and faster ablation period "Castle, et al.; Floridi, et al., (2011, 2014)" over the other ablation therapy types which also offers lifeline to patients who surgery cannot be carried out on, faster recovery period and reduced cost "Woldu, et al.; Long, et al., (2015, 2016)" over surgery and partial nephrectomy has made it a focus of continuous study by researchers.

Having undertaken studies on the influence of catheter material on the degree of thermal necrosis that can be achieved with a co-axial antenna, and the impact of the antenna slot size and position, this study aims to determine the effect of the number of antenna slots on the extent of thermal lesion that can be achieved in a liver tissue during microwave ablation therapy procedure.

\section{MATERIALS AND METHODS}

The antenna slot size and position having been shown from previous studies to be a significant contributor to its performance are now investigated with the use of a fixed slot size and relative position but with the use of a varying numbers of slots. This was investigated using the microwave therapy for cancer as developed by COMSOL Multiphysics for a coaxial slot geometry.

Using Tefzel ETFE as the catheter material "Towoju and Petinrin (2018)", setting the initial temperature of blood to $37^{\circ} \mathrm{C}$, and a frequency of $2.45 \mathrm{GHz}$, the simulation was carried out to determine the temperature distribution in the liver at the tumour site for several number of slots ranging from one to six.

A screenshot of the model is shown in figure 1.

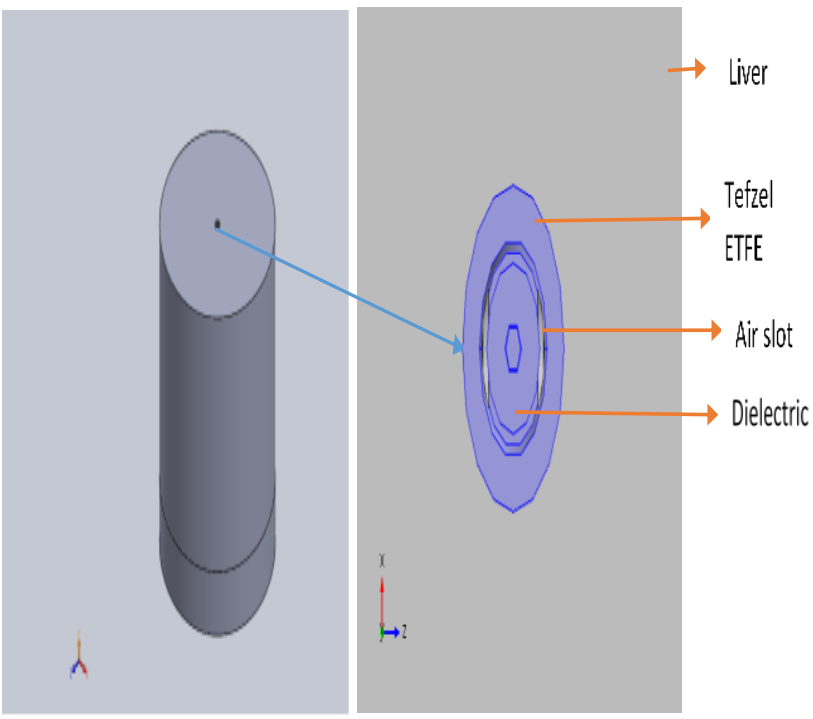

Fig. 1. Three-dimension View of The Coaxial Antenna in The Liver
The properties of the antenna materials depicted in figure 1 are stated in Table 1, the dimensions are as stated in Table 2, while Table 3 gives the properties of the biomaterials; the liver and blood.

Table 1. Coaxial Antenna Material Properties

\begin{tabular}{|c|c|}
\hline $\begin{array}{c}\text { Antenna } \\
\text { Material }\end{array}$ & $\begin{array}{c}\text { Relative } \\
\text { Permittivity }\end{array}$ \\
\hline Dielectric & 2.03 \\
\hline Tefzel ETFE & 2.311 \\
\hline
\end{tabular}

Table 2. Coaxial Antenna Material Dimensions

\begin{tabular}{|c|c|}
\hline Antenna Parts & Value (m) \\
\hline Central conductor diameter & 0.00029 \\
\hline Dielectric outer diameter & 0.00094 \\
\hline Outer conductor outer diameter & 0.00190 \\
\hline Tefzel ETFE outer diameter & 0.00179 \\
\hline
\end{tabular}

Table 3. Properties of the Biomaterials

\begin{tabular}{|c|c|}
\hline Biomaterial Parameter & Value \\
\hline Density of blood $\left(\mathrm{kg} / \mathrm{m}^{3}\right)$ & 1045 \\
\hline Blood perfusion rate $(1 / \mathrm{s})$ & 0.0036 \\
\hline Specific heat of blood $(\mathrm{J} / \mathrm{kgK})$ & 3639 \\
\hline Relative permittivity of liver & 43.03 \\
\hline Conductivity of liver $(\mathrm{S} / \mathrm{m})$ & 1.69 \\
\hline
\end{tabular}

The model geometry is such that it can be expanded into mutually orthogonal modes and thus the higher diffraction orders can be accounted for with the use of the absorbing port boundary and scattering conditions. This allows for the truncation of the model geometry without the introduction of large errors.

Electromagnetic radiation is to be generated by the antenna, therefore, necessitating the need for the application of special low-reflecting boundary conditions in the order of a few wavelengths away from any source. The electric field has a finite axial component and the magnetic field is purely in the azimuthal direction in the tissue allowing the antenna to be modelled using the axisymmetric transverse magnetic formulation;

$$
H_{\varphi 0}=\sqrt{\frac{-n x \sqrt{\varepsilon E}+\sqrt{\left.\mu H_{\varphi}\right)}}{4 \mu^{2}}}
$$

The interior of the metallic conductors is not model and the tangential component of the electric field is set to zero to incorporate the conductor by employing the perfect electric conductor boundary condition.

The transverse electromagnetic fields characterize the electromagnetic wave propagation, and the governing equations are given as;

$$
\begin{aligned}
& E(\alpha)=e_{r} \frac{c}{r} e^{j(\omega t-k z)} \\
& H(\alpha)=e_{\varphi} \frac{C}{z} e^{j(\omega t-k z)}
\end{aligned}
$$




$$
C=\sqrt{\frac{P_{i} X}{e_{z} \pi I n\left(\frac{r_{0}}{r_{i}}\right)}}
$$

The angular frequency ' $\omega$ ' is related to the propagation constant ' $\mathrm{k}$ ' by the expression;

$$
\omega=k V
$$

where $r o$ and $r \mathrm{i}$ are the dielectric outer and inner radii, $\mathrm{X}$ is the dielectric wave impedance, $P_{\mathrm{i}}$ is the input power, $\mathrm{r}, \varphi$, and $\mathrm{z}$ are the coaxial cable cylindrical coordinates.

The heat transfer in the liver is time-dependent and is governed by the bio-heat transfer equation neglecting the heat generation from metabolism as stated in equation 6 , and the antenna Specific Absorption Rate (SAR) is derived with equation 7 ;

$$
\begin{gathered}
\rho C_{p} \frac{\partial T}{\partial t}+\nabla \cdot(-k \nabla T)=\rho_{b 1} C_{b 1} \omega_{b 1}\left(T_{b 1}-T\right)+Q_{a x} \\
S A R=\frac{\sigma}{2 p}\lceil E\rceil^{2}
\end{gathered}
$$

where $Q_{e x}$ is the external heat source which is equal to the resistive heat generated by the electromagnetic field, $C_{b \mathbb{D}}$ is blood specific heat capacity, and is $p_{b 1}$ the blood density, $T_{b D}$ is the temperature of blood, $\omega_{b l}$ is the blood perfusion rate, $\mathrm{k}$ is the thermal conductivity of tissue, and $\sigma$ is the tissue conductivity.

The fraction of the tissue that undergoes necrosis is derived using the relation;

$$
\emptyset_{n}=1-e(-\alpha)
$$

$-\alpha$ is the tissue extent of injury.

The geometry of the modelled coaxial antenna utilized in the microwave ablation of the liver tumour is shown in figure 2 .

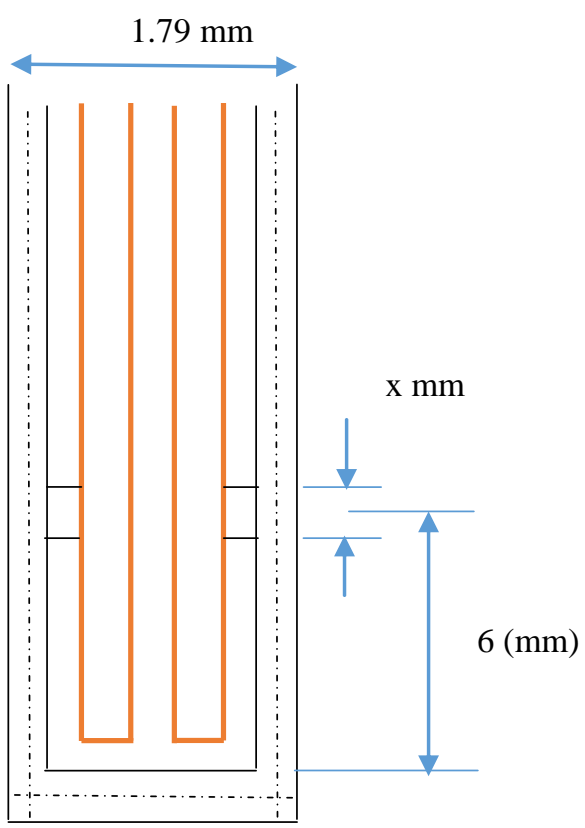

Fig. 2. The Geometry of The Coaxial Antenna "Towoju, et al. (2019)"

The slot number and their corresponding sizes are shown in Table 4.

Table 4. Dimension of the slot

\begin{tabular}{|c|c|}
\hline Slot number & Dimension (mm) \\
\hline 1 & 0.900 \\
\hline 2 & 0.450 \\
\hline 3 & 0.300 \\
\hline 4 & 0.225 \\
\hline 5 & 0.180 \\
\hline 6 & 0.150 \\
\hline
\end{tabular}

III. RESULT AND DISCUSSION

The effect of using several numbers of slots against a single one was investigated in this study. The relative slot position was $6 \mathrm{~mm}$ from the antenna tip based on the findings of previous studies being the position of optimized performance "Towoju, et al., (2019)".

The antenna slot diameter was maintained at $0.9 \mathrm{~mm}$, however, the slot number was varied from one to six to determine the effect on its performance. The number of slots and the antenna performance was evaluated based on the fraction of necrotic tissue after twenty minutes of the ablation procedure. This was carried out for the cases of cumulative slot length of $1.05 \mathrm{~mm}$ along the antenna vertical axis and slot separating gap of $0.03 \mathrm{~mm}$.

The resulting simulation plots of the total power dissipation density for the two studied conditions are shown in Figures 3 and 4 respectively.

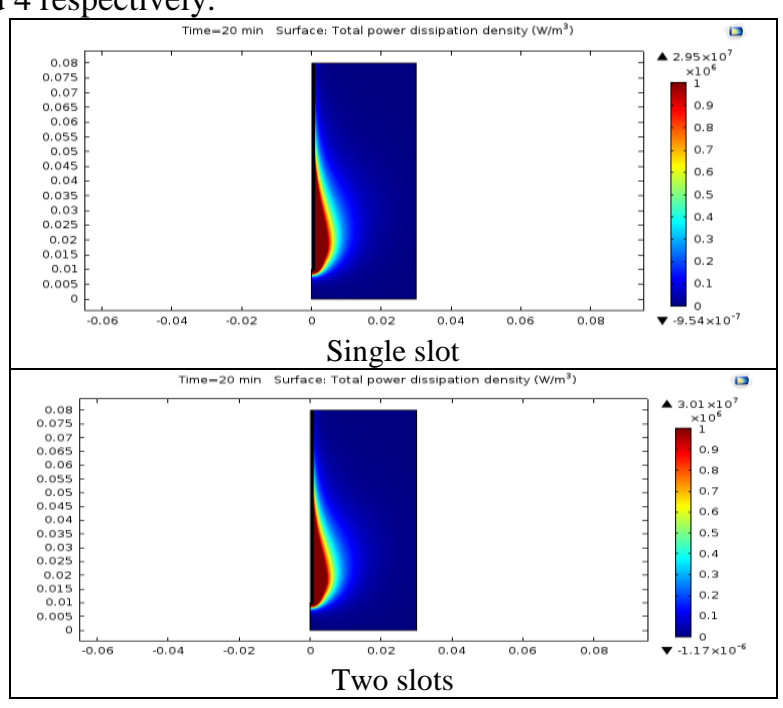


Published Online August 2019 in IJEAST (http://www.ijeast.com)

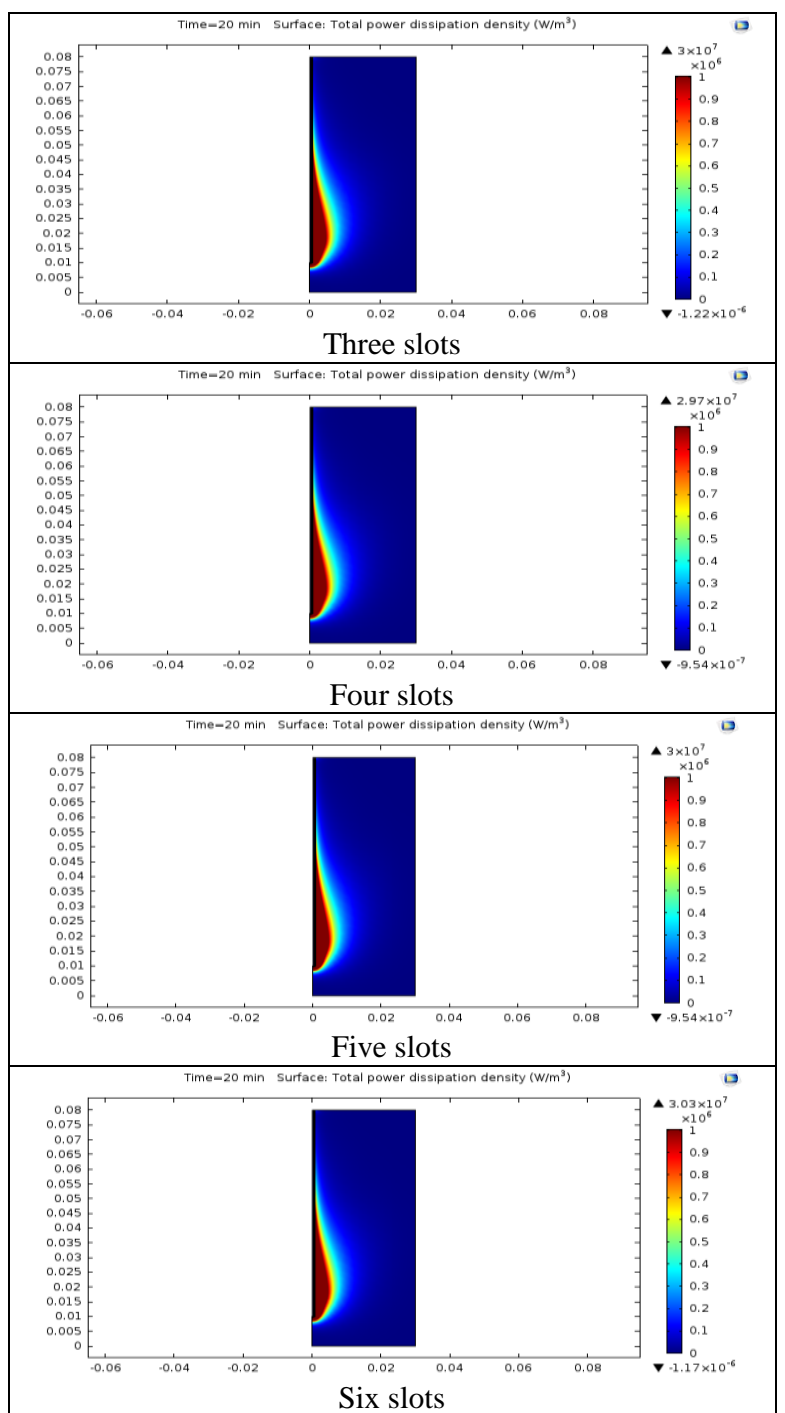

Fig.3. Total Power Dissipation Density Plots for Cummulative Slot Length of $1.05 \mathrm{~mm}$

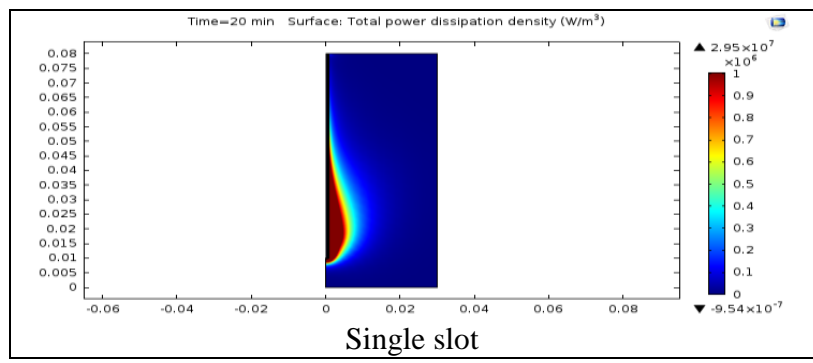

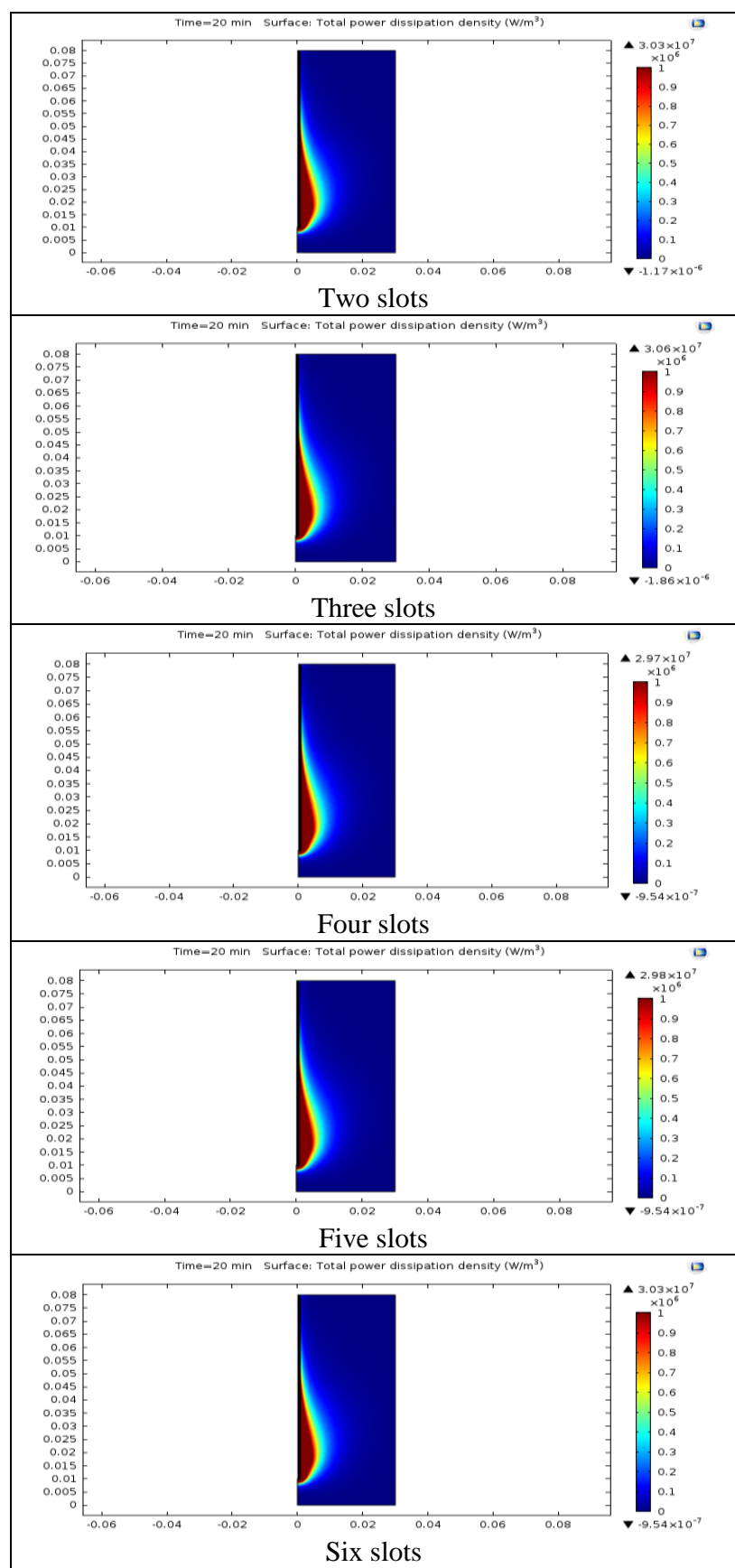

Fig. 4. Total Power Dissipation Density Plots for Slots Gap of $0.03 \mathrm{~mm}$

Figure 5 gives the total power dissipation density values for the varying number of slots for the condition where the length of the slots along the antenna vertical axis is $1.05 \mathrm{~mm}$, and where a gap of $0.03 \mathrm{~mm}$ is maintained between the slots. 


\section{International Journal of Engineering Applied Sciences and Technology, 2019 Vol. 4, Issue 4, ISSN No. 2455-2143, Pages 6-11 \\ Published Online August 2019 in IJEAST (http://www.ijeast.com)}

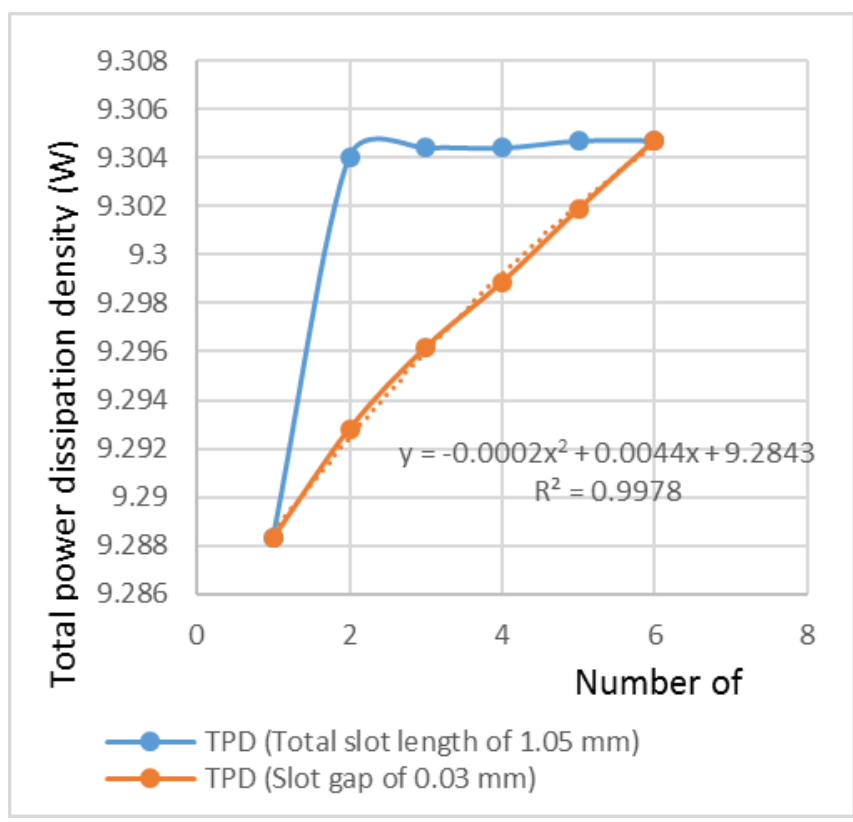

Fig. 5. Total Power Dissipation Density Values in The Liver

For the case where a constant gap of $0.03 \mathrm{~mm}$ was maintained between individual slots along the vertical axis, the total power dissipation density followed a regular pattern of an increment with the increase of the number of slots. The total power dissipation density for any number of slots with a separation distance of $0.03 \mathrm{~mm}$ can be derived by using the polynomial function with a high degree of accuracy judging from the high value of $\mathrm{R}^{2}$;

$$
y=\left(-0.0002 x^{2}+0.0044 x+9.2843\right) W
$$

The total power dissipation density increases from one slot to three slots after which subsequent changes takes on an irregular pattern as the number of slot increases for the condition where the total slot length along the antenna vertical axis was $1.05 \mathrm{~mm}$. For slots of two and above, the total power dissipation density during microwave ablation using the modelled antenna can be predicted with the equation;

$$
y=\left(-0.00003 x^{2}+0.0004 x+9.3034\right) W
$$

The higher the fraction of the input power that can be absorbed by the tissue, the higher will be the microwave ablation therapy efficacy in the thermal lesson of the tumour; the amount of energy available for heating, that is an increment in temperature increases with is dependent on the total power dissipation density.

\section{CONCLUSION}

The total power dissipation density during microwave ablation can be increased with an increase in the number of slots if the separation gap between slots is maintained at a constant value. However, this cannot be said for the case of maintaining a constant slot length along the vertical axis of the coaxial antenna.
The efficiency of the antenna utilized in microwave ablation therapy is increased with the use of an increased number of slots for a constant slot separation distance.

\section{REFERENCE}

Baere, T., and Deschamps, F. (2014). New Tumors Ablation Techniques for Cancer Treatment (Microwave, Electroporation). Diagnostic and Interventional Imaging, 95, (pp. 677-682).

Bertram, J. M., Yang, D., Converse, M. C., Webster, J. G., and Mahvi, D. M. (2006). Antenna Design for Microwave Hepatic Ablation Using Axisymmetric Electromagnetic Model. BioMedical Engineering Online, 5(15), (pp. 1-9).

Bettaeib, A., and Averill-Bates, D. A. (2015). Thermotolerance Induced at a Mild Temperature $40^{\circ} \mathrm{C}$ Alleviates Heat Shock-Induced ER Stress and Apoptosis in HeLa Cells. Biochimica et Biophysica Acta, 1853, ( pp. 52-62).

Brace, C. L. (2010a). Microwave Ablation Technology: What Every Use Should Know. Curr Probl Daign Radiol, 38(2), (pp. 61-67).

Brace, C. L. (2010b). Microwave Tissue Ablation: Biophysics, Technology and Applications. Crit RevBiomed Eng., 38(1), (pp. 65-78).

Campbell, S. C., Novick, A., Belldegrun, M. L., and Blute. (2009). Guideline for management of the clinical T1 renal mass. J Urol, 182, (pp. 1271-1279).

Castle, S. M., Salas, N., and Leveillee, R. J. (2011). Initial Experience Using Microwave Ablation Therapy for Renal Tumor Treatment: 18-Month Follow-up. Urology, 4, (pp. 792-797).

Cornelis, F. H., Marcelin, C., and Bernhard, J. C. (2017). Microwave Ablation of Renal Tumors: A Narrative Review of Technical Considerations and Clinical Results. Diagnostics and Interventional Imaging, 98, (pp. 287297).

Deshazer, G., Prakash, P., Merck, D., and Haemmerich, D. (2017). Experimental Measurement of Microwave Ablation Heating and Comparison to Computer Simulations. Int J Hyperthermia, 33, (pp. 74-82).

Floridi, C., De Bernardi, L., and Fontana, F. (2014). Microwave Ablation of Renal Tumors: State of the Art and Development Trends. Radiol Med, 119, (pp. 533540).

Gao, H., Wu, S., Wang, X., Hu, R., Zhou, Z., and Sun, X. (2017). Temperature Simulation of Microwave Ablation Based on Improved Specific Absorption Rate Compared to Phantom Measurements. Computer Assisted Surgery, 22(S1), (pp. 9-17).

Higgins, L. J., and Hong, K. (2015). Renal Ablation Techniques: State of the Art. AJR, 205, (pp. 735-741). 
Ibitoye, A. Z., Orotoye, T., Nwoye, E. O., and Aweda, M. A. (2018). Analysis of Efficiency of Different Antennas for Microwave Ablation Using Simulation and Experimental Methods. Egyptian Journal of Basic and Applied Sciences, 5, (pp. 24-30).

Lerardi, A. M., Mangano, A., Floridi, C., Dionigi, G., et al. (2015). A New System of Microwave Ablation at 2450 MHz: Preliminary Experience. Updates Surg, 67, (pp. 3945).

Li, F. M., Chen, F. Z., and Li, W. G. (2017). Progress in ablation therapy of liver cancer. Shijie Huaren Xiaohua Zazhi, 25(27), (pp. 2427-2432), doi:org/10.11569/wcjd. v25.i27.2427.

Long, J. A., Bernhard, J. C., Pigot, C., et al. (2016). Partial Nephrectomy versus Ablative Therapy for the Treatment of Renal Tumors in an Imperative Setting. World J Urol, 35, (pp. 649-656).

Prakash, P. (2010). Theoretical Modeling for Hepatic Microwave Ablation. The Open Biomedical Engineering Journal, 4, (pp. 27-38).

Seror, O. (2015). Ablative Therapies: Advantages and Disadvantages of Radiofrequency, Cryotherapy, Microwave and Electroporation Methods, or How to Choose the Right Method for an Individual Patient? Diagnostics and Interventional Imaging, 96, (pp. 617624).

Towoju, O. A., and Petinrin, M. O. (2018). Thermal Lesion of Renal Tumour as a Function of Catheter Material Property. European Journal of Engineering Research and Science, 3(9), (pp. 12-17), DOI: http://dx.doi.org/10.24018/ejers.2018.3.9.886.

Towoju, O. A., Ishola, F. A., Sanni, T., and Soji-Adekunle, R. (2019). Coaxial Antenna Slot Impact on Thermal Effectiveness in Microwave Ablation Therapy. International Journal of Scientific and Technology Research, 8(6), (pp. 30-36).

Woldu, S. L., Thoreson, G. R., Okhunov, Z., Ghandour, R., Rothberg, M. B., RoyChoudhury, A., and McKieman, J. M. (2015). Comparison of Renal Parenchymal Volume Preservation Between Partial Nephrectomy, Croablation, and Radiofrequency Ablation Using 3D Volume Measurements. J Endourol., 29(8), (pp. 948-955). 